\title{
ANAESTHETIC MANAGEMENT OF MYOCARDIAL RIGHT VENTRICULAR HYDATID CYST EXCISION
}

Bodicherla Siva Kumar ${ }^{1}$

\section{HOW TO CITE THIS ARTICLE:}

Bodicherla Siva Kumar "Anaesthetic Management of Myocardial Right Ventricular Hydatid Cyst Excision". Journal of Evolution of Medical and Dental Sciences 2015; Vol. 4, Issue 82, October 12; Page: 14422-14426, DOI: $10.14260 /$ jemds/2015/2051

ABSTRACT: Hydatid cyst is caused by the larva of Echinococcus species characterized by slow growing cyst in visceral organs. The actual prevalence of hydatid disease in southern part of India is found more than usually interpreted. This paper presents a case report of 26 year old lady with myocardial hydatid cyst which was totally excised under cardiopulmonary bypass surgery. Anaesthesiologists has to be aware of and be ready to manage the challenges like anaphylaxis due to leakage of cyst fluid into the surrounding tissues. One should be pharmacologically and electrically (Cardioversion) well equipped to tackle arrythmias. Our most important anaesthetic goal was to maintain sinus rhythm, adequate cardiac output and perfusion pressure, during the entire perioperative period. Early diagnosis and intervention are crucial for successful management of the anaphylactic reactions.

KEYWORDS: Hydatid cyst, right ventricle, anaphylactic shock.

KEYMESSAGES: Anesthetic management of myocardial right ventricular hydatid cyst excision.

INTRODUCTION: Hydatid cyst is due to Echinococcus species-Cestode Parasite. There are predominantly two species affecting the human population; Echinococcus granulosus and Echinococcus multilocularis causing Cystic Echinococcosis (Hydatid disease) and Alveolar Echinococcosis respectively. In India highest prevalence is reported from Andhra Pradesh and Tamilnadu.[1,2] This cyclozoonotic disease continues to be the most vexing socioeconomic problem in many partsof the world. ${ }^{[3]}$ Although the disease is eradicated in mostof the parts of the world, it still remains a serious endemic health problem in developing countries. ${ }^{[4,5]}$ The exact percentage of site involvement varies and the exact incidence of unusual locations is difficult to ascertain as they are only reported as case reports. In $10 \%$ cases, hydatid disease arises in the viscera; mainly in the spleen (0.9-8\%) and also in kidney, bone, heart muscles and peritoneal cavity $(0.5-5 \%) .{ }^{[6]}$

CASE HISTORY: A 26 year old female was referred to our facility because of complaints of chest pain and exertional dyspnea that had occurred over the course of the previous six months. Transthoracic echocardiography and CT chest revealed a large cystic mass in right ventricle measuring $5.5 \times 4.0 \mathrm{~cm}$ abutting the anterior wall of right ventricle (Figure 1). A general physical examination found nothing abnormal, and the patient had no cardiac murmers. Electrocardiography (ECG) showed sinus rythum with right bundle branch block, tachycardia (Figure 2) and ultra sound scan of whole abdomen showed no obvious sonological abnormality. Based on these findings, surgery was recommended.

The patient was pre-medicated with inj. Pethidine 50mg and inj. Phenargan 25mg I.M one hour before the procedure. I.V lines secured and all monitors were connected. Base line readings were recorded. 


\section{CASE REPORT}

Patient was pre-oxygenated with $100 \%$ oxygen for 5 min and was induced with inj. propofol after pre-medicating with inj. glycopyrrolate $0.2 \mathrm{mg}$ I.V, Inj. midazolam $2 \mathrm{mg}$ I.V, Inj. Fentanyl $150 \mathrm{mcg}$ to attenuate the pressor responses. Intubating dose of inj. Rocuronium 50mg I.V was given. After confirming adequate relaxation, intubation was performed with 7.5 no. cuffed portex endotracheal tube. Anaesthesia was maintained with 100\% 02 and intermittent doses of Inj. Vecuronium and inj. Fentanyl. The patient underwent aortic arterial bicaval cannulation after a median sternotomy and a right ventriculotomy was performed after aortic cross clamping. The cystic mass was detected in the right ventricle which was slightly narrowing the right ventricular outlet tract (Figure 3). With a syringe, 50cc of fluid was aspirated from the cyst. The cyst wall and the vesicles were removed and ventriculotomy was then primarily closed (Figure 4). The perioperative and postoperative periods were problem free. The patient was on sinus rhythm and no blocks were observed. Albendazole treatment was given to decrease the risk of relapse. The patient was discharged on the post-operative seventh day without complications, but the albendazole treatment was continued for one month.

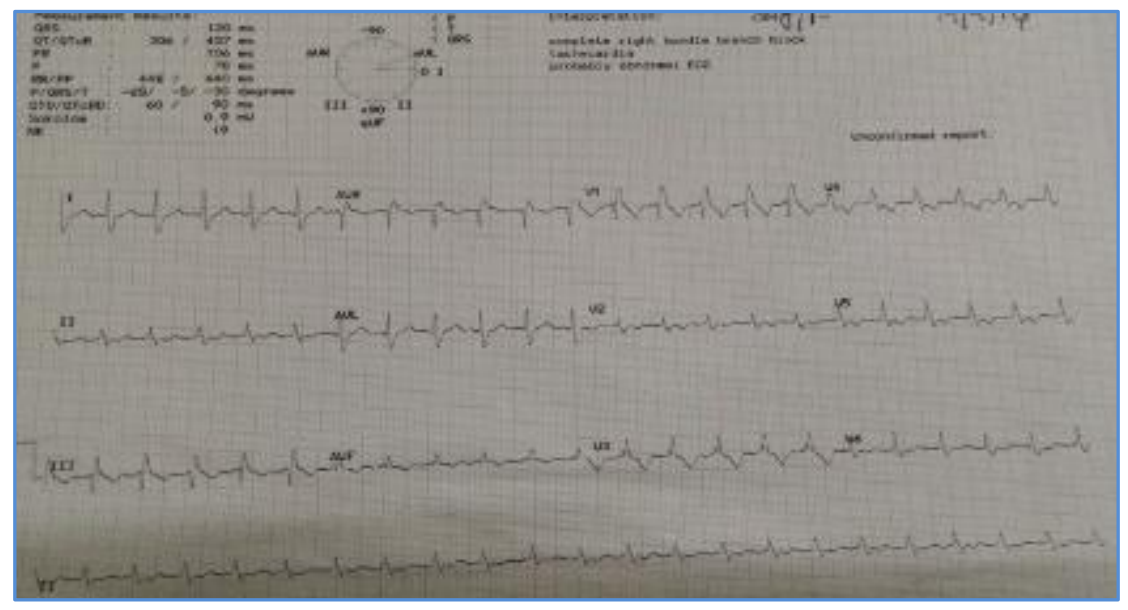

\section{Fig. 1: ECG showing RBBB and Tachycardia}
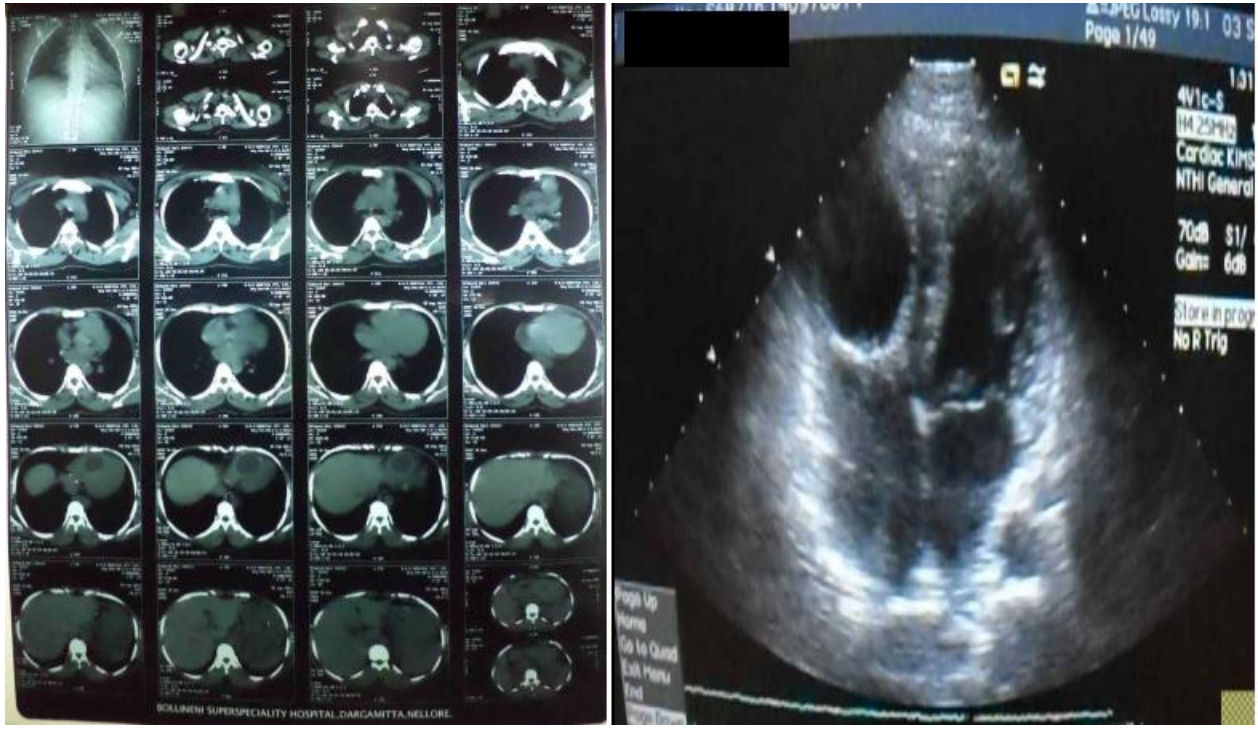

Fig. 2: CT chest and 2D ECHO showing right ventricular cyst 


\section{CASE REPORT}

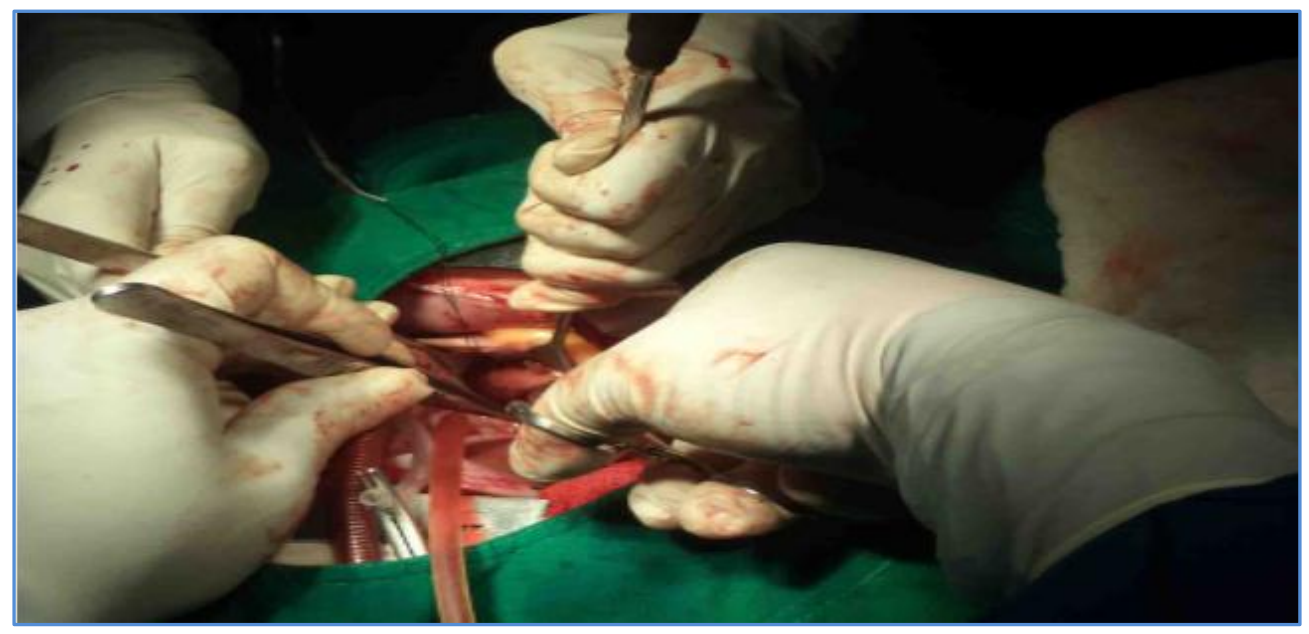

Fig. 3: View of cyst through right ventriculotomy

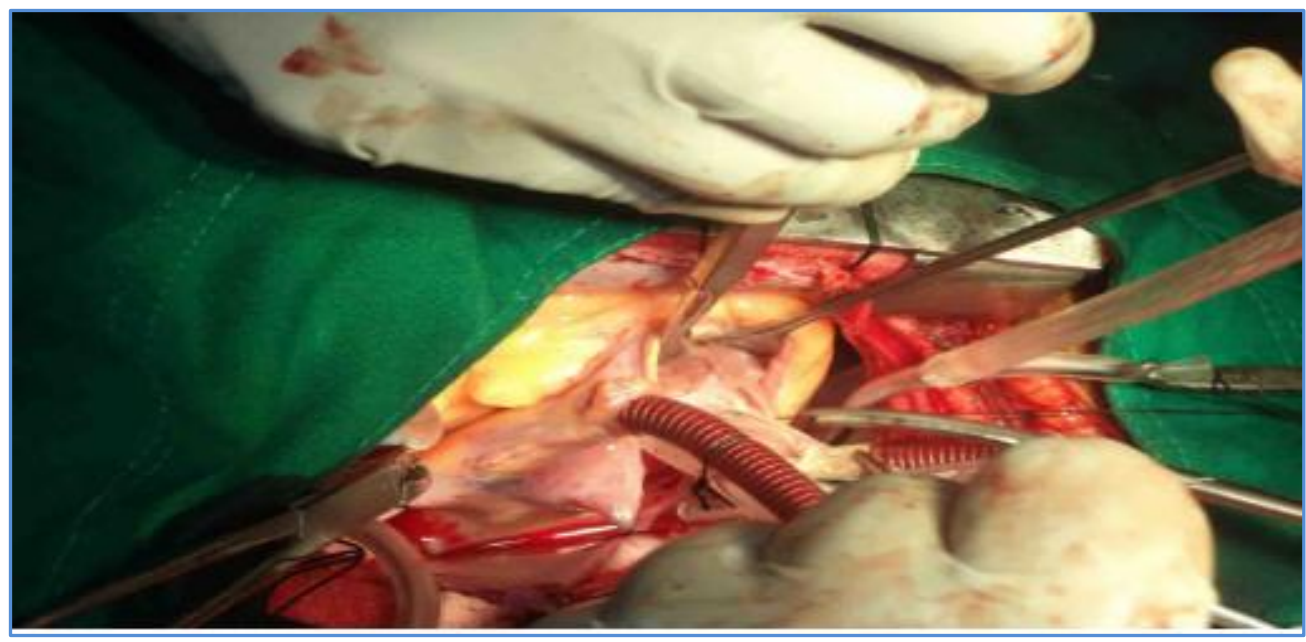

Fig. 4: View of interventricular septum with cyst removed

DISCUSSION: Cardiac hydatid cyst disease comprises $2 \%$ of all hydatid cyst cases. The most common localization is the left ventricle (55-60\%), ${ }^{[7]}$ with the right ventricle, left atrium, pulmonary artery, pericardium (7-8\%), and interventricular septum (8\%) being less commonly involved. The disease may be asymptomatic or may present with clinical findings owing to the number, localization, and size of the cysts. In hydatid cysts located in the interventricular septum, disturbances of rhythm and hemodynamics, atrioventricular block due to compression on conduction pathways, and right or left ventricular outlet tract obstruction may be seen. ${ }^{[8]}$ In our case, the cyst was located in the right ventricle abutting the anterior wall of right ventricle and was slightly narrowing the right ventricular outlet tract. Cysts located in the left ventricle may cause T-wave changes and low QRS voltage. In our case, right bundle branch block was found via ECG. Angina, pulmonary hypertension, and cardiac valve dysfunctions have also been reported depending on the localization of the lesion. Complications such as anaphylaxis and pulmonary or systemic embolism may also be seen, and early diagnosis of the disease is vital for preventing their occurrence. ${ }^{[9]}$ 
In a patient diagnosed with cardiac hydatid cyst disease, the treatment of choice is surgery because of the risk of rupture and anaphylactic shock. Furthermore, the cyst could also rupture into the pericardial cavity and cause pericardial effusion and cardiac tamponade.

In determining the most appropriate surgical technique, localization of the cyst is of great importance. Because of the difficulty in using the surgical approach for isolated ventricular cysts, the best method is excision with cardiopulmonary bypass (CPB). However, if the cyst ruptures, it potentially could cause lethal events such as embolism and anaphylactic shock.[10] We chose to perform the surgical excision under CPB after careful consideration. The postoperative ECG showed sinus rhythm, and the ejection fraction was $62 \%$.

In conclusion, hydatid cyst disease may be isolated in the heart and can cause various clinical scenarios depending on the localization and size of the lesions. We think that because of the risk of sudden death, the most effective treatment in cardiac hydatid cyst cases is surgery since the morbidity rates are low. Because rare cases of relapsing cardiac hydatid cyst disease have been reported, medical treatment following surgery is a must, and the cases should be followed up periodically with different imaging methods.

\section{REFERENCES:}

1. Reddy CR, Narasiah IL, Parvathi G, Rao MS. Epidemiology of Hydatid disease in Kurnool. IndianJ Med Res 1968; 55: 499-507.

2. Amir Jahed, A. K., Fardin, R., Farzad, A., Bakshandeh, K. Clinical echinococcosis. Ann Surg 1975; 182(5):541-6.

3. S.E. Al Barwari, I.S. Saeed, W. Khalid, K.I. AlHarmni. Human Hydatidosis in Arbil, N. Iraq. Jour Islamic Aca Sci 1991; 4:330-5.

4. Erman T, Tuna M, Gocer I, Ildan F, Zeren M,Cetinalp E. Intracranial intraosseous hydatid cyst. Case report and review of literature. NeurosurgFocus 2001; 11(1):ECP1.

5. McManus DP, Zhang W, Li J, Bartley PB. Echinococcosis. Lancet 2003; 18 (362):1295-1304 Doi :10.1016/S0140-6736(03)14573-4.

6. Zippi M, Siliquini F, Fierro A, et al. Diffuse abdominal hydatidosis: role of magnetic resonance imaging. Clin Ter 2007; 158 (3):231-3.

7. Murphy TE, Kean BH, Venturini A, Lillehei CW. Echinococcus cyst of the left ventricle. Report of a case with review of the pertinent literature. J Thorac Cardiovasc Surg 1971; 61:443-50.

8. Eren EE, Aykut S, Kayihan A, Aydogan H, Dagsali S. Echinococcal cyst of the interventricular septum with right ventricular protrusion. Tex Heart Inst J 1989; 16:292-5.

9. Kabbani SS, Jokhadar M, Sundouk A, Nabhani F, Baba B, Shafik AI. Surgical management of cardiac echinococcosis. Report of four cases. J Cardiovasc Surg (Torino) 1992; 33:505-10.

10. Bashour TT, Alali AR, Mason DT, Saalouke M. Echinococcosis of the heart: clinical and echocardiographic features in 19 patients. Am Heart J 1996; 132: 1028-30. 


\section{AUTHORS:}

1. Bodicherla Siva Kumar

\section{PARTICULARS OF CONTRIBUTORS:}

1. Assistant Professor, Department of Anaesthesia and Critical Care, Mallareddy Institute of Medical Sciences, Hyderabad.

FINANCIAL OR OTHER

COMPETING INTERESTS: None

\section{NAME ADDRESS EMAIL ID OF THE} CORRESPONDING AUTHOR:

Bodicherla Siva Kumar, Mallareddy Institute of Medical Sciences, Sy. No. 138, Suraram Main Road, GHMC Quthbullapur Jeedimetla, Hyderabad - 500055, Telangana

E-mail: avis_dr@yahoo.com

Date of Submission: 18/09/2015. Date of Peer Review: 19/09/2015. Date of Acceptance: 01/10/2015. Date of Publishing: 12/10/2015. 